\title{
Effects of a group activity-based motivational enhancement therapy program on social media addictive behaviors among junior high school students in Thailand: a cluster randomized trial
}

This article was published in the following Dove Press journal:

Psychology Research and Behavior Management

\author{
Mereerat Manwong ${ }^{1,2}$ \\ Vitool Lohsoonthorn' \\ Thanvaruj Booranasuksakul ${ }^{3}$ \\ Anun Chaikoolvatana ${ }^{2}$ \\ 'Department of Preventive and \\ Social Medicine, Faculty of Medicine, \\ Chulalongkorn University, Bangkok, \\ Thailand; ${ }^{2}$ College of Medicine and \\ Public Health, Ubon Ratchathani \\ University, Ubon Ratchathani \\ Province, Thailand; ${ }^{3}$ Department of \\ Psychiatry, Faculty of Medicine, King \\ Chulalongkorn Memorial Hospital, \\ Bangkok, Thailand
}

Purpose: This study aimed to assess the effects of a group activity-based motivational enhancement therapy (GA-MET) program on social media addictive behaviors among junior high school students.

Materials and methods: This cluster randomized trial was performed in 245 junior high school students who used social media in the lower part of northeast Thailand. The GA-MET program group and the control group sessions lasted 8 weeks and were followed up 4 weeks later. The addictive social media behaviors, average duration of social media usage during weekdays and weekends (hours/day), child behaviors, self-esteem, and depression were investigated using a self-reported questionnaire. Multivariable linear regression was used to compare the mean and 95\% CIs between two groups.

Results: The GA-MET program significantly decreased the average duration of social media usage during weekdays and weekends (hours/day) $(-1.27,95 \% \mathrm{CI}:-2.18,-0.37$ and $-1.25,95 \%$ CI: $-2.22,-0.29$, respectively), emotional behavior $(-0.69,95 \%$ CI: -1.18 , $-0.19)$, and depression $(-4.03,95 \% \mathrm{CI}:-6.07,-1.99)$ in the treated group compared to the control group.

Conclusion: The GA-MET program could reduce the risk of social media addictive behaviors in junior high school students in Thailand by decreasing time spent on social media, emotional behaviors, and depression.

Keywords: group activities, motivational enhancement therapy (MET), social media addictive behavior, students, Thailand, social media addiction

\section{Introduction}

Social network sites (SNSs) are convenient and easily accessible communication channel. Due to the increasing number of SNSs, social media use has increased by $21 \%$ since January 2016, ${ }^{1}$ especially among younger people. ${ }^{2,3}$ However, excessive use of social media can negatively affect daily life activities, such as social activities, studies/ job, ${ }^{4-7}$ interpersonal relationships,${ }^{8,9}$ psychological health, ${ }^{2,10-16}$ and well-being. ${ }^{3}$ Devoting too much time to SNSs may also lead to social media addictive (SMA) behaviors. ${ }^{8}$ Originally, there was no category for diagnostic SMA behavior as a disease in the Diagnostic and Statistical Manual of Mental Disorders, but it has currently been added as a new behavioral addiction. ${ }^{8}$
Correspondence: Vitool Lohsoonthorn Department of Preventive and Social Medicine, OPR Building, Floor 19, Faculty of Medicine, Chulalongkorn University, 1873 Rama 4 Road, Pathumwan, Bangkok 10330, Thailand

Tel +66 22527864

Email vitool@gmail.com 
Since obsession with social media can have multiple negative effects on daily life, prevention and treatment of SMA behaviors are crucial. Existing studies have focused mostly on games and Internet addiction interventions. For example, a cluster randomized controlled trial on the effects of a brief school-based media literacy intervention on computer gaming and Internet use behavior in adolescents indicated that intervention decreased self-reported gaming frequency, gaming time, proportion of excessive gamers, group time, addictive gaming, and Internet addiction. ${ }^{17}$ Furthermore, a meta-analysis on the treatment of Internet addiction showed no differences between pharmacological and psychological approaches. ${ }^{18}$ Several studies treated Internet and game addiction using cognitive-behavioral therapy. ${ }^{8,18,19}$ The motivational enhancement therapy (MET) via motivational interviewing (MI) technique is an effective client-centered approach to change SMA behaviors beyond cognitive-behavioral therapy. ${ }^{20}$ This technique uses openended questions, affirmation, reflective, listening, and summarization. The meta-analysis showed the positive effects of MI on health problems, such as alcohol abuse, smoking cessation, drug addiction, HIV risk behavior, and diet/exercise problems. ${ }^{21,22}$ Nevertheless, no studies have used MI to address SMA behaviors. ${ }^{8}$ To the best of our knowledge, we are among the first to adopt this approach to prevent SMA behaviors in adolescents in Southeast Asia. Accordingly, this study aimed to assess the effects of a group activities-based MET (GA-MET) program among junior high school students by measuring score changes of SMA behaviors, duration of social media use on weekdays and weekends, child behavior, self-esteem, and depression.

\section{Materials and methods Study design}

This study used a two-arm cluster randomized trial with three assessments (baseline, immediate effect: week 8, follow-up: week 12). The trial was registered at clinicaltrials.in.th (identifier: TCTR20170124001) on January 24, 2017.

\section{Study procedure}

We calculated the sample size for cluster randomized controlled trials with a fixed number of clusters. ${ }^{23}$ We defined the difference of the SMA behavior score between the groups as three scores because there is no previous study about SMA behavior change, and $\sigma^{2}=15.74 .{ }^{19}$ Intraclass correlation coefficient of 0.05 was assumed. ${ }^{24}$ Thirty students were recruited from each classroom. An alpha error of 0.05 and a power of 0.90 were used, allowing for a loss to follow-up of $10 \%$, indicating that the number of participants and classrooms per arm should be 100 and 4, respectively. In November 2016, 20 randomly selected seventh and eighth grade classrooms from a high school in Ubon Ratchathani province in the Lower part of northeast Thailand were invited to participate in the study. Sixteen classrooms agreed to join the study. Simple randomization was performed to divide the classrooms into experimental and control groups, with four classes in each group. Parents received information about the study along with a written informed consent form, and they were given the option to either sign the informed consent form or to refuse their child's participation. The study was conducted from December 2016 to March 2017. The Ethics Committee of the Faculty of Medicine, Chulalongkorn University approved this study (reference no. 406/59) on October 13, 2016.

\section{Sample}

Thai seventh and eighth grade high school students (12-15 years of age) who used SNS (eg, Facebook, Line, Instagram, WhatsApp, or YouTube, among others), expressed their interest to participate, and obtained a signed parental informed consent form were included. Students also had to meet the following criteria: 1) had studied for more than one semester in school; 2) had never been treated for Internet, game, or SMA; 3) had never been treated for depressive disorder; and 4) both parents and students agreed to participate. Based on the medical history reported by the participants or their parents, if the participants had any diseases or physical or mental health problems, including attention-deficit/hyperactive disorder, learning disorders, mental retardation, and depressive disorder, they were excluded.

Eight classrooms with a total of 253 students agreed to participate and met the inclusion criteria of this study. From the original total of 317 students, 1 student who had been treated for game addiction and 8 who had attention-deficit/hyperactive disorder were excluded. Of all eligible students, $2.4 \%(n=6)$ did not participate following the first activity and $0.8 \%(n=2)$ resigned from school. The retention rate was $96.8 \%(n=245)$ at the immediate effect (week 8) and $96.4 \%(\mathrm{n}=244)$ at the follow-up (week 12) (0.4\%: $n=1$, resigned). The final sample comprised 244 students with complete data at all measurements (total dropout rate was 3.6\%), as shown in Figure 1.

\section{Control group}

Students who participated in regular school activities (eg, consultation or education with classroom teachers on issues related to learning, living, relationship with friends, among others) formed the control group. The control group did not 


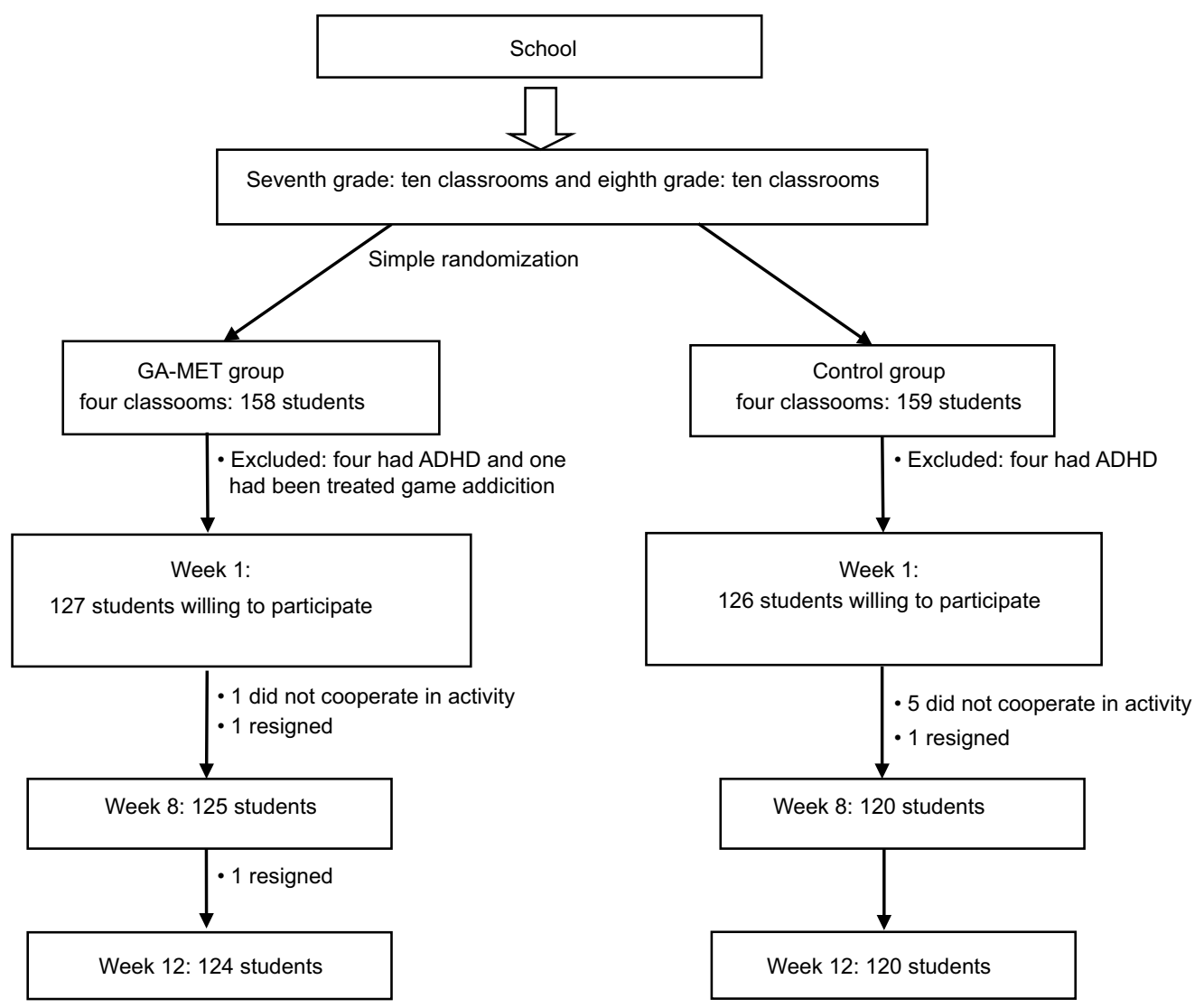

Figure I Study flow chart.

Abbreviations: ADHD, attention-deficit/hyperactive disorder; GA-MET, group activity-based motivational enhancement therapy.

participate in the GA-MET program, and their data were collected at baseline, week 8 , and week 12 , as were the data of the intervention group.

\section{Intervention}

The author and a child and an adolescent psychiatrist developed a GA-MET program in three steps. The first step involved reviewing the related literature. The second step involved evaluation of the GA-MET program's content and construct validities by five experts, two child and adolescent psychiatrists, two clinical psychologists, and one MI/MET expert, using the index of item objective congruence $>0.5$. Each GA-MET program activity had an average index of item objective congruence between 0.54 and 0.74 . The last step involved applying the program in another school to test the appropriateness of the format, content, duration, and priority. Subsequently, the program was revised prior to the current trial. There were three phases as follows: Phase I: the education and feedback phase, Phase II: the commitment and strengthening phase, and Phase III: the follow-up phase. Eight activities were conducted in Phases I and II. For the GA-MET program, under the supervision of the child and adolescent psychiatrist, the participants were divided into groups of eight to ten students. Each activity was performed in each classroom for 45-50 minutes/week via a facilitator who was either the author, a clinical psychologist, or a behaviorist with experience consulting or educating adolescents about health in a school environment. They were all trained in MI/MET and the GA-MET programs. After completing the activities, each group summarized the activities and the facilitator responded to the participants' questions.

Phase I (health education and feedback) involved four activities: 1) ice breaking, 2) group discussion about the definition of social media and the experience of using social media, 3) watching short movies about SMA behavior in adolescents followed by a group discussion of pros and cons, after which the experimental participants did a selfassessment to determine their SMA levels and a researcher individually informed them of their SMA status, and 4) sharing by the experimental participants of their experiences about the effects of social media use, which included a discussion and concluded with a group learning session. These four activities were conducted over the first 4 weeks of the study. The goal was to increase participants' motivation to change their behaviors from pre-contemplation and contemplation to preparation stage. Phase II (commitment and 
strengthening) consisted of activity numbers 5-8 as follows: 5) a researcher queried about the experience of refraining from social media use in order to share the optional choice of reducing social media use behavior, 6) this activity was used to indicate the difference in the present behaviors and the goal of behavior change in their lives. A small group was assigned to determine whether individuals were addicted to social media or not addicted and to share their perception of the future SMA effects with the class later, 7) each group selected one of three role play situations and performed a role play, followed by reflection among the class members in preparation for the action stage of SMA behavior change, and 8) to remind themselves of and recognize the goal of changing SMA behavior, each participant received a card for writing their goal. Next, the cards were shown in the front of their classroom to remind the participants of the goal to change their social media behavior. This phase aimed to increase motivation and determine the appropriate approach to change participants' social media behaviors and their commitment through group activities. This phase targeted the participants who were motivated to move on to the preparation and action stages of change and included activity number 5 through number 8 which were completed in week 5-8. Phase III (follow through) aimed to assess whether students follow through on their decision to change their SMA behavior, review their goals, overcome obstacles, check commitment, and improve motivation, focusing on progression from the action to the maintenance stage. The outcomes were assessed 4 weeks later to determine the sustainability of the result of this study.

\section{Measures}

The participants and their parents agreed to participate in this study by giving their signed informed consent. A code was used to protect the privacy of all participants. Each participant sat privately during the self-report assessment to feel free to access his or her responses and to maintain the confidentiality of individuals' data. The study questionnaire of consisted of five parts. There were five parts to the selfreporting questionnaire, as follows: SMA behaviors, average duration of the social media use on weekdays and weekends, self-esteem, depression, and covariates. A sixth part, child behaviors, was reported by a classroom teacher.

"SMA behaviors" was used to sort students into three categories: 1) not addicted, 2) almost addicted, and 3) addicted. Students were asked to assess their social media behaviors using the Social Media Addiction Test (S-MAT). It comprises 16 items measuring the symptoms of SMA behaviors, including excessive use of social media, loss of control over social media usage, and functional impairment. The measurement is on a 4-point scale (not at all, not really, maybe right, and absolutely) ranging from 0 to 3 , with higher scores indicating more severity. The total score ranged from 0 to 48 , with the following cutoff points: $0-19=$ not addicted, $20-29=$ almost addicted, and 30 and over $=$ addicted. The internal consistency reliability (Cronbach's alpha) was $0.898 .{ }^{14}$

For "average duration of the social media use on weekdays and weekends", students were asked to estimate how long they spend on social media on weekdays and weekends (hours/day).

For “child behaviors", students' strong and difficult behaviors were assessed using the teacher-reported Thai Strengths and Difficulties Questionnaire (SDQ). The questionnaire comprises 25 items measuring five categories: 1) emotional behaviors, 2) hyperactivities/attention deficit, 3) unruly behavior, 4) peer relationship, and 5) social relationship, which are scored on a 3-point scale ranging from 0 to 2 (false, rather true, and absolutely). ${ }^{25}$

For "self-esteem", students completed the Thai version of the Rosenberg Self-esteem Scale comprising ten items which measure self-esteem on a 4-point Likert scale ranging from strongly disagree (1) to strongly agree (4). The total score ranges from 10 to 40 , with higher scores indicating high self-esteem. ${ }^{26}$

For "depression", students completed the Thai version of the Center for Epidemiologic Studies-Depression scale assessing depression in adolescents in the previous week. It comprises 20 items rated on a 4-point Likert scale ranging from 0 to 3 (never, sometimes: 1-2 days/week, seldom: 3-4 days/week, and always: 5-7 days/week). The total score ranges from 0 to 60 , with a cutoff point of 22 indicating depression. The internal consistency (Cronbach's alpha) of the scale was 0.86 , sensitivity was $72 \%$, specificity was $85 \%$, and accuracy was $82 \%{ }^{27}$

For "covariates", a self-administered questionnaire was used to assess sociodemographic covariates of age, gender, education level, cumulative grade point average, number of relatives, family status, ${ }^{28}$ income, parenting style (ie, ignoring, strict, indulgent, and free to an extent), and family relationship (ie, closeness, estrangement, and quarrel). ${ }^{29}$ The social media use question assessed the most popular social media devices used to access social media (ie, smartphone, tablet/iPad, notebook, and computer), sources available to access social media at home and outside the home (ie, LAN, WiFi/edge, and $3 \mathrm{G} / 4 \mathrm{G}$ ), communication with parents, and parental control over adolescents' use of social media (ie, not controlled, sometimes, and strictly). In addition, we 
assessed the frequency with which adolescents engaged in social media activities, such as contacting friends, seeking a girl/boyfriend, finding new friends, meeting more attractive friends, posting pictures, sharing reports or homework, and contacting teachers, among others, using a 3-point scale (never/hardly, sometimes, and always).

\section{Statistical analyses}

All analyses were performed using STATA/IC version 14.0 for Windows. The frequency distributions, mean (SD), minimum and maximum for continuous variables, and numbers and percentages for categorical variables were used to examine sociodemographic characteristics and social media behaviors for each group. The Fisher's exact test for categorical data and independent $t$-test for continuous data were used to determine differences in sociodemographic and social media behaviors between the GA-MET and control groups. We used multivariable linear regression to compare the mean and $95 \%$ CIs of the adjusted variables of average duration of social media use on weekdays at baseline (hours/ day) and the types of social media activities at weeks 8 and 12. Additionally, the SMA behavior was analyzed by three subgroups according to S-MAT score (ie, not addicted, almost addicted, and addicted groups). All reported $P$-values were two-sided, and statistical significance was set at the 0.05 level.

\section{Results}

Overall, 125 students were in the experimental group and 120 were in the control group. The baseline characteristics in both groups were similar (Table 1). The most popular social media sites were Facebook, Line, and Instagram. The social media behaviors of both groups were similar, with most participants using social media mostly via smartphone $(83 \%)$, followed by $3 \mathrm{G} / 4 \mathrm{G}(\sim 70 \%)$ outside the home and WiFi/EDGE $(<50 \%)$ at home. In addition, $>60 \%$ were using social media to connect with their parents and $75 \%-80 \%$ used social media only sometimes under parental restrictions. Four distinct social media activities were differentiated between groups: seeking a girl/boyfriend, finding new friends, meeting more attractive friends, and contacting teachers (Table 2).

The unadjusted mean for all outcomes by group are presented in Table 3. At baseline, differences in all outcomes were nonsignificant, except for an average duration of social media use during weekdays, as the GA-MET group reported significantly higher duration time compared to the control group. For immediate effect (week 8), groups differed only in the average duration of social media use during weekdays and weekends. For sustained effect (week 12), time spent using social media on weekdays and weekends differed across groups. Moreover, the GA-MET and control groups differed in unruly behavior, self-esteem, and depression.

Multivariable linear regression analyses revealed the effects of program on different social media activities after adjusting for duration of social media use during weekdays at baseline (Table 3). For immediate effect (week 8), the GA-MET group scored lower on average duration of social media use on the weekdays by 0.91 (95\% CI: $0.15,1.67)$ of an hour per day or 55 minutes per day and by 0.84 of an hour per day or 50 minutes per day for weekends (95\% CI: 0.04, 1.64). Another immediate effect on the SDQ for GA-MET group decreased by a score of 0.69 (95\% CI: 0.19, 1.18) compared to the control group. For sustained effect (week 12), the GA-MET group reported lower average duration of social media usage during weekdays of 1.27 hours per day or 75 minutes (95\% CI: 0.37, 2.18). For weekends, the lower average duration of social media usage was 1.25 hours per day or 75 minutes per day $(95 \%$ CI: $0.29,2.22)$ compared to the control group. In addition, the depression scores were also reduced significantly in the GA-MET group by a score of 4.03 (95\% CI: 1.99, 6.07) compared with the control group (Table 3 ).

Table 4 presents the adjusted mean for all outcomes by subgroup of baseline SMA behaviors. In the not addicted group, the average duration of social media use during weekdays and the depression score were significantly lower in the GA-MET group as compared to the control group at weeks 8 and 12. In the almost addicted group, the average duration of social media usage during weekdays decreased by 1.44 hours per day or 85 minutes per day ( $95 \% \mathrm{CI}:-0.34$, $3.23)$, compared to the control group for the sustained effect. In the addicted group, the average duration of social media usage during weekdays was lower by 2.39 hours per day or 140 minutes per day $(95 \% \mathrm{CI}:-0.13,4.91)$ compared to that of the control group for the immediate effect only.

\section{Discussion}

To the best of our knowledge, this study is the first to investigate the role of the GA-MET program in the prevention or treatment of SMA behaviors in Southeast Asia. We found that the GA-MET program effectively decreased the average duration of social media usage on weekdays and weekends, emotional behaviors, and depression scores in the GA-MET group, especially in the not addicted and almost addicted subgroups of SMA behavior. Each phase of the GA-MET program was designed to raise participants' awareness of and motivation to change SMA behavior via organized 
Table I Baseline characteristic of participants

\begin{tabular}{|c|c|c|c|c|c|}
\hline \multirow[t]{2}{*}{ Characteristics } & \multicolumn{2}{|c|}{ GA-MET group $(n=\mid 25)$} & \multicolumn{2}{|c|}{ Control group $(n=120)$} & \multirow[t]{2}{*}{$P$-value ${ }^{b}$} \\
\hline & Number $^{a}$ & (\%) & Number $^{a}$ & (\%) & \\
\hline Age (years) & & & & & 0.171 \\
\hline 12 & 12 & 9.6 & 18 & 15.0 & \\
\hline 13 & 64 & 51.2 & 48 & 40.0 & \\
\hline 14 & 49 & 39.2 & 53 & 44.2 & \\
\hline 15 & 0 & 0.0 & I & 0.8 & \\
\hline Gender & & & & & 0.610 \\
\hline Male & 57 & 45.6 & 59 & 49.2 & \\
\hline Female & 68 & 54.4 & 61 & 50.8 & \\
\hline Educational level & & & & & 0.701 \\
\hline Seventh grade & 61 & 48.8 & 55 & 45.8 & \\
\hline Eighth grade & 64 & 51.2 & 65 & 54.2 & \\
\hline GPAX & & & & & 0.229 \\
\hline Min.-Max. & $0.97-3.94$ & & $0.76-3.91$ & & \\
\hline Mean (SD) & $2.46(0.72)$ & & $2.58(0.72)$ & & \\
\hline No. of relatives & & & & & 0.538 \\
\hline No & 17 & 13.6 & 13 & 10.8 & \\
\hline One sibling & 59 & 47.2 & 52 & 43.3 & \\
\hline Two or more siblings & 49 & 39.2 & 55 & 45.8 & \\
\hline Family status & & & & & 0.305 \\
\hline Living together & 84 & 67.2 & 78 & 65.0 & \\
\hline Divorced & 28 & 22.4 & 33 & 27.5 & \\
\hline Separated & 10 & 8.0 & 4 & 3.3 & \\
\hline Father or mother died & 3 & 2.4 & 5 & 4.2 & \\
\hline Sufficient income & & & & & 0.684 \\
\hline Not enough & 4 & 3.4 & 2 & 1.8 & \\
\hline Enough & 115 & 96.6 & 112 & 98.2 & \\
\hline Living with & & & & & 0.402 \\
\hline Parents & 79 & 63.2 & 71 & 59.2 & \\
\hline Father or mother & 22 & 17.6 & 29 & 24.2 & \\
\hline Friends & 0 & 0.0 & I & 0.8 & \\
\hline Relative & 24 & 19.2 & 19 & 15.8 & \\
\hline Parenting style & & & & & 0.457 \\
\hline Ignore & 2 & 1.6 & 4 & 3.4 & \\
\hline Strictly & 96 & 76.8 & 88 & 74.6 & \\
\hline Indulgent & 27 & 21.6 & 24 & 20.3 & \\
\hline Free to the extent & 0 & 0.0 & 2 & 1.7 & \\
\hline Family relationships & & & & & 0.228 \\
\hline Closeness & 116 & 93.6 & 114 & 97.4 & \\
\hline Estrangement & 6 & 4.8 & 1 & 0.9 & \\
\hline Quarrel & 2 & 1.6 & 2 & 1.7 & \\
\hline
\end{tabular}

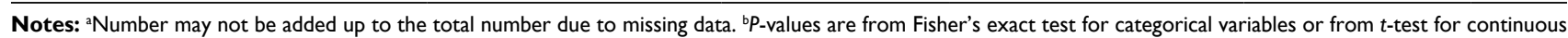
variables.

Abbreviations: GA-MET, group activity-based motivational enhancement therapy; GPAX, cumulative grade point average.

group activities. This allowed the participants to learn group roles, such as working together, listening to each other, and exchanging experiences, as well as engaging in individual activities such as drawing, analyzing video clips, and role playing, among others. The activities in this study differ from those used in traditional classroom settings, which may have affected students' emotional behavior (ie, they reported that the activities were fun and exciting) and depression scores, ${ }^{18}$ and were related to previous studies which revealed the effect of group MI on depression. ${ }^{30-32}$ In addition, the participants in all subgroups of SMA behavior completed the learning activities, which reflected both the real world and the virtual world and, consequently, decreased emotional behavior and depression, as confirmed in many previous studies on SMA and depression. ${ }^{11,13,14,19,33-37}$ Because SMA behaviors are based on the addiction paradigm, ${ }^{8}$ spending more time on the 
Table 2 Social media behavior of participants

\begin{tabular}{|c|c|c|c|c|c|}
\hline \multirow[t]{2}{*}{ Social media behavior } & \multicolumn{2}{|c|}{ GA-MET group $(n=125)$} & \multicolumn{2}{|c|}{ Control group $(n=120)$} & \multirow[t]{2}{*}{$P$-value ${ }^{\text {b }}$} \\
\hline & Number ${ }^{a}$ & $(\%)$ & Number ${ }^{a}$ & $(\%)$ & \\
\hline Devices for access social media & & & & & 0.999 \\
\hline Smartphone & 103 & 83.1 & 99 & 83.2 & \\
\hline Tablet/iPad & 3 & 2.4 & 3 & 2.5 & \\
\hline Notebook & 6 & 4.8 & 6 & 5.0 & \\
\hline Computer & 12 & 9.7 & 11 & 9.2 & \\
\hline Source for access social media at home & & & & & 0.185 \\
\hline LAN & 4 & 3.2 & 0 & 0.0 & \\
\hline WiFi/EDGE & 78 & 62.4 & 76 & 63.3 & \\
\hline $3 G / 4 G$ & 43 & 34.4 & 44 & 36.7 & \\
\hline Source for access social media outside & & & & & 0.117 \\
\hline LAN & 4 & 3.2 & I & 0.8 & \\
\hline WiFi/EDGE & 22 & 17.6 & 33 & 27.5 & \\
\hline $3 G / 4 G$ & 99 & 79.2 & 86 & 71.7 & \\
\hline Communicate with parents & & & & & 0.508 \\
\hline Not using & 43 & 34.4 & 46 & 38.7 & \\
\hline Using & 82 & 65.6 & 73 & 61.3 & \\
\hline Parental control over adolescents' use of social media & & & & & 0.245 \\
\hline Not controlled & 12 & 9.7 & 13 & 10.8 & \\
\hline Sometimes & 93 & 75.0 & 97 & 80.8 & \\
\hline Strict & 19 & 15.3 & 10 & 8.3 & \\
\hline Seeking a girl/boyfriend & & & & & 0.030 \\
\hline Never/hardly & 92 & 73.6 & 93 & 77.5 & \\
\hline Sometimes & 18 & 14.4 & 23 & 19.2 & \\
\hline Always & 15 & 12.0 & 4 & 3.3 & \\
\hline Find new friends & & & & & 0.043 \\
\hline Never/hardly & 60 & 48.0 & 71 & 59.2 & \\
\hline Sometimes & 40 & 32.0 & 38 & 31.7 & \\
\hline Always & 25 & 20.0 & II & 9.2 & \\
\hline Meeting more attractive friends & & & & & 0.037 \\
\hline Never/hardly & 61 & 48.8 & 78 & 65.0 & \\
\hline Sometimes & 48 & 38.4 & 33 & 27.5 & \\
\hline Always & 16 & 12.8 & 9 & 7.5 & \\
\hline Contacting teachers & & & & & 0.018 \\
\hline Never/hardly & 41 & 32.8 & 59 & 49.2 & \\
\hline Sometimes & 56 & 44.8 & 46 & 38.3 & \\
\hline Always & 28 & 22.4 & 15 & 12.5 & \\
\hline
\end{tabular}

Notes: aNumber may not be added up to the total number due to missing data. ${ }^{b} P$-values are from Fisher's exact test.

Abbreviation: GA-MET, group activity-based motivational enhancement therapy.

social media sites increases the risk of SMA. ${ }^{38}$ Therefore, this program was designed to enhance participants' motivation to change their SMA behavior, reduce their total time spent on social media, and suppress the addictive SMA behavior. In addition to providing support for the effectiveness of the program, the results further confirm the recommendation that, instead of enforcing total abstinence, other interventions can be employed. SMA behavior is not like other addictions such as smoking, drinking, and drug abuse. Today's society allows for easy access to the Internet and use of social media; thus, it is not possible to stop people from using these technologies in their daily life. However, various studies show that the monitoring of SMA can be achieved by measuring Internet access duration via computer, mobile phone, and other devices. ${ }^{18,33,39}$

This program could not detect SMA behaviors, since the time between initial measurement with the S-MAT and the follow-ups was short. However, evidence from the metaanalysis found that most research on Internet addiction utilizes treatment which lasts from 5 to 16 hours (mean=12.44, $\mathrm{SD}=4.89$ ), with follow-up periods ranging from 1.5 to 6 months (mean=4.13, SD=2.25). ${ }^{18}$ The activities in this study took about 6-7 hours to complete, which is consistent with previous studies and MET therapy, although the follow-up 
Table 3 Comparison of the effects of program by group

\begin{tabular}{|c|c|c|c|c|}
\hline \multirow[t]{2}{*}{ Outcome } & \multicolumn{2}{|l|}{ Mean (SD) } & \multirow{2}{*}{$\begin{array}{l}\text { Unadjusted mean } \\
\text { difference }(95 \% \mathrm{Cl})\end{array}$} & \multirow{2}{*}{$\begin{array}{l}\text { Adjusted mean } \\
\text { difference }^{a}(95 \% \mathrm{Cl})\end{array}$} \\
\hline & $\begin{array}{l}\text { GA-MET } \\
\text { group } \\
(n=\mid 25)\end{array}$ & $\begin{array}{l}\text { Control } \\
\text { group } \\
(n=\mid 20)\end{array}$ & & \\
\hline \multicolumn{5}{|c|}{ Social media addictive behavior scores } \\
\hline Baseline & $20.02(9.00)$ & $21.16(9.23)$ & & \\
\hline Week 8 & $20.62(8.28)$ & $21.13(9.06)$ & $-0.5 \mathrm{I}(-2.68, \mathrm{I} .69)$ & $-0.13(-1.99,1.74)$ \\
\hline Week 12 & $19.21(9.83)$ & $20.59(10.02)$ & $-1.38(-3.88,1.12)$ & $-1.27(-3.47,0.93)$ \\
\hline \multicolumn{5}{|c|}{ Average duration of social media } \\
\hline Baseline & $5.23(3.03)$ & $4.47(2.89)$ & & \\
\hline Week 8 & $4.94(3.17)$ & $4.88(2.97)$ & $0.06(-0.71,0.84)^{*}$ & $-0.91(-1.67,-0.15)^{*}$ \\
\hline Week 12 & $5.61(3.62)$ & $5.85(3.28)$ & $-0.24(-1.11,0.63)^{*}$ & $-1.27(-2.18,-0.37)^{* *}$ \\
\hline \multicolumn{5}{|c|}{ Average duration of social media } \\
\hline Baseline & $6.96(3.89)$ & $6.30(3.80)$ & & \\
\hline Week 8 & $6.64(3.88)$ & $6.81(3.91)$ & $-0.17(-1.15,0.81)$ & $-0.84(-1.64,-0.04)^{*}$ \\
\hline Week 12 & $7.40(4.38)$ & $7.68(4.56)$ & $-0.28(-1.40,0.85)$ & $-1.25(-2.22,-0.29)^{*}$ \\
\hline \multicolumn{5}{|l|}{ SDQ scores } \\
\hline Baseline & II.57 (5.37) & $11.63(5.03)$ & & \\
\hline Week 8 & II.42 (5.62) & $11.92(5.24)$ & $-0.50(-1.86,0.87)$ & $-0.80(-1.92,0.31)$ \\
\hline Week 12 & II.82 (6.04) & $|3.0|(5.57)$ & $-1.19(-2.65,0.28)$ & $-1.17(-2.53,0.19)$ \\
\hline \multicolumn{5}{|c|}{ I. SDQ scores part I: emotional } \\
\hline \multicolumn{5}{|l|}{ behavior } \\
\hline Baseline & $3.05(2.07)$ & $3.14(2.11)$ & & \\
\hline Week 8 & $2.75(2.24)$ & $3.28(2.14)$ & $-0.53(-1.10,0.04)$ & $-0.69(-1.18,-0.19)^{* *}$ \\
\hline Week 12 & $2.74(2.35)$ & $3.15(2.16)$ & $-0.41(-0.98,0.18)$ & $-0.43(-0.99,0.12)$ \\
\hline \multicolumn{5}{|c|}{$\begin{array}{l}\text { 2. SDQ scores part 2: hyperactivities/ } \\
\text { attention deficit }\end{array}$} \\
\hline Baseline & $2.99(1.56)$ & $2.77(\mathrm{l} .44)$ & & \\
\hline Week 8 & $2.90(1.48)$ & $2.89(1.47)$ & $0.01(-0.38,0.39)$ & $-0.08(-0.44,0.28)$ \\
\hline Week 12 & $3.13(1.63)$ & $3.34(I .7 I)$ & $-0.21(-0.63,0.22)$ & $-0.34(-0.76,0.08)$ \\
\hline \multicolumn{5}{|c|}{ 3. SDQ scores part 3: unruly behavior } \\
\hline Baseline & $2.93(2.16)$ & $3.28(1.96)$ & & \\
\hline Week 8 & $2.84(1.98)$ & $3.04(1.86)$ & $-0.20(-0.70,0.31)$ & $-0.09(-0.53,0.34)$ \\
\hline Week 12 & $2.79(1.98)$ & $3.41(1.86)$ & $-0.62(-1.13,-0.13)^{*}$ & $-0.39(-0.86,0.08)$ \\
\hline \multicolumn{5}{|c|}{ 4. SDQ scores part 4: peer } \\
\hline \multicolumn{5}{|l|}{ relationship } \\
\hline Baseline & $2.60(1.55)$ & $2.50(I .5 I)$ & & \\
\hline Week 8 & $2.82(1.74)$ & $2.65(\mathrm{I} .5 \mathrm{I})$ & $0.17(-0.26,0.58)$ & $-0.01(-0.37,0.37)$ \\
\hline Week 12 & $3.03(1.76)$ & $3.14(1.70)$ & $-0.11(-0.55,0.34)$ & $-0.16(-0.60,0.27)$ \\
\hline \multicolumn{5}{|c|}{ 5. SDQ scores part 5: social } \\
\hline \multicolumn{5}{|l|}{ relationship } \\
\hline Baseline & $5.7 I(I .8 I)$ & $5.79(1.66)$ & & \\
\hline Week 8 & $5.93(1.77)$ & $5.74(1.84)$ & $0.19(-0.27,0.66)$ & $0.20(-0.23,0.63)$ \\
\hline Week 12 & $5.77(1.97)$ & $5.54(1.93)$ & $0.23(-0.28,0.72)$ & $0.16(-0.32,0.64)$ \\
\hline \multicolumn{5}{|c|}{ Self-esteem scores } \\
\hline Baseline & $28.02(3.53)$ & $27.47(3.73)$ & & \\
\hline Week 8 & $28.30(3.92)$ & $27.32(4.07)$ & $0.98(-0.03,1.98)$ & $0.69(-0.18,1.56)$ \\
\hline Week 12 & $28.14(3.67)$ & $27.10(3.64)$ & $1.04(0.12,1.97)^{*}$ & $0.76(-0.08,1.59)$ \\
\hline \multicolumn{5}{|c|}{ Depression scores } \\
\hline Baseline & $13.45(8.49)$ & | $3.87(7.75)$ & & \\
\hline Week 8 & $14.65(9.59)$ & $15.97(9.04)$ & $-1.32(-3.67,1.02)$ & $-1.65(-3.74,0.44)$ \\
\hline Week 12 & $14.19(8.76)$ & $18.07(8.64)$ & $-3.88(-6.07,-1.69)^{*}$ & $-4.03(-6.07,-1.99) * *$ \\
\hline
\end{tabular}

Notes: *Significant at $P<0.05$, **Significant at $P<0.01$. aAdjusted for duration of social media usage during weekday at baseline (hours/day). Social media activities included seeking a girl/boyfriend, finding new friends, meeting more attractive friends, contacting teachers, and baseline values of each outcome.

Abbreviations: GA-MET, group activity-based motivational enhancement therapy; SDQ, Strength and Difficulty Questionnaire. 
Table 4 Comparison of the effects of GA-MET program by subgroup of baseline SMA behavior

\begin{tabular}{|c|c|c|c|}
\hline \multirow[t]{3}{*}{ Outcome } & \multicolumn{3}{|c|}{ Subgroups of baseline SMA behavior } \\
\hline & Not addicted $(n=122)$ & Almost addicted $(n=80)$ & Addicted $(n=43)$ \\
\hline & Mean difference $^{a}(95 \% \mathrm{Cl})$ & Mean difference $^{a}(95 \% \mathrm{Cl})$ & Mean difference $^{a}(95 \% \mathrm{Cl})$ \\
\hline \multicolumn{4}{|c|}{ SMA behavior scores } \\
\hline Week 8 & $-0.11(-2.75,2.52)$ & $0.07(-3.52,3.66)$ & $-2.00(-8.72,4.72)$ \\
\hline Week 12 & $-1.85(-4.98,1.29)$ & $1.84(-1.85,5.53)$ & $-1.85(-10.21,6.5 \mathrm{I})$ \\
\hline \multicolumn{4}{|c|}{$\begin{array}{l}\text { Average duration of social media } \\
\text { usage during weekday (hours/day) }\end{array}$} \\
\hline Week 8 & $-1.08(-2.13,-0.02)^{*}$ & $-1.14(-2.63,0.35)$ & $0.68(-1.40,2.76)$ \\
\hline Week 12 & $-1.60(-2.71,-0.49)^{* *}$ & $-1.44(-3.23,0.34)$ & $0.46(-2.57,3.50)$ \\
\hline \multirow{2}{*}{\multicolumn{4}{|c|}{$\begin{array}{l}\text { Average duration of social media } \\
\text { usage during weekend (hours/day) }\end{array}$}} \\
\hline & & & \\
\hline Week 8 & $0.12(-1.17,1.41)$ & $-1.5 \mid(-3.21,0.18)$ & $-2.39(-4.91,0.13)$ \\
\hline Week 12 & $-0.91(-2.32,0.50)$ & $-1.20(-3.21,0.80)$ & $-1.82(-4.60,0.97)$ \\
\hline \multicolumn{4}{|l|}{ SDQ scores } \\
\hline Week 8 & $-0.98(-2.50,0.54)$ & $-0.42(-2.81,1.97)$ & $-2.09(-5.40,1.23)$ \\
\hline Week 12 & $-1.50(-3.49,0.50)$ & $0.53(-2.05,3.12)$ & $0.30(-4.46,5.07)$ \\
\hline \multicolumn{4}{|c|}{ Self-esteem scores } \\
\hline Week 8 & $1.06(-0.30,2.4 I)$ & $0.67(-1.20,2.54)$ & $0.74(-0.55,2.03)$ \\
\hline Week 12 & $0.66(-0.60,1.93)$ & $0.03(-1.68,1.75)$ & $0.86(-0.74,2.45)$ \\
\hline \multicolumn{4}{|c|}{ Depression scores } \\
\hline Week 8 & $-2.99(-5.88,-0.10)^{*}$ & $-1.28(-6.04,3.49)$ & $1.27(-3.96,6.50)$ \\
\hline Week 12 & $-4.4 \mathrm{I}(-7.39,-1.43)^{* *}$ & $-1.24(-5.02,2.54)$ & $-5.15(-12.12,1.82)$ \\
\hline
\end{tabular}

Notes: aAjusted for duration of social media usage during weekday at baseline (hours/day). Social media activities included seeking a girl/boyfriend, finding new friends, meeting more attractive friends, contacting teachers, and baseline values of each outcome. Coding: GA-MET group $=I$ and control group $=0$. $*$ Significant at $P<0.05$, ** significant at $P<0.0$ I.

Abbreviations: GA-MET, group activity-based motivational enhancement therapy; SDQ, Strength and Difficulty Questionnaire; SMA, social media addictive.

periods may have been too short. In addition, we found that students engage in many other activities in school beyond those addressed in this study (ie, open house, sport day activities, girl scout parades, integrated activities, etc), which affect the continuity of behavior change. Furthermore, after the participants finished activity 6 , they argued that the major barriers to behavior change were friends, environment, and daily living. This suggests that the GA-MET program may be more suitable for prevention rather than treatment of SMA behaviors. Therefore, further study should investigate additional strategies or other treatments which would involve parents and consider the rules about using social media in schools (self-report upon the completion of activity 6). This study also found that, although the self-esteem of the participants in two groups differed slightly, no differences emerged after adjusting for confounding factor at week 12 . Lastly, the GA-MET program did not reduce the self-esteem of the participants who already had low self-esteem.

The strengths of this study include the large number of participants in each group with a relatively high retention rate (96.8\%), which provided sufficient statistical power to detect differences. These results were based on adjusted baseline characteristics and other important covariates which were not balanced. The findings can be used to promote engagement in activities associated with social media use in school. The GA-MET program should be included in the seventh grade health education course with no more than three groups (eight to ten students/group) in a classroom, specifically covering the effects of excessive social media use, SMA behaviors, and the methods to change social media use. However, this study has several limitations. First, all activities were conducted during homeroom period in a conference room or outdoors; therefore, the control group may have been exposed to but not affected by these activities, as the control group participants did not know the content of the activities, which they only observed from a distance. Second, the GA-MET program significantly reduced social media use behavior only in the not addicted group. Also, because this study computed the sample size in all of the SMA behaviors, the almost addicted and addicted groups had inadequate sample sizes to obviously detect differences in the parameters. There was also a limitation concerning the insufficient sample size of subgroups. 
Third, the participants, for the most part, did self-assessment, except for the part of the SDQ which was assessed by classroom teachers. The teachers and participants were willing to participate in this study and provided their signed informed consent. However, for the average time of the use of social media on weekdays and weekends, the measurements may have been affected by over- or underreporting as a result of recall bias or social desirability bias. Finally, this study was conducted in an urban junior high school context in Thailand; therefore, these findings may be limited to representing the urban, but not the rural areas.

\section{Conclusion}

This study showed that the GA-MET program can be used to prevent SMA behaviors, as it decreased the time spent on using social media, emotional behavior, and depression. Future research should implement this program in other schools and add more supportive strategies to find the appropriate approach to treat SMA behaviors, especially in an addicted group.

\section{Acknowledgments}

The 90th anniversary of Chulalongkorn University Fund and the Thesis Grant for Doctoral Degree Student of the National Research Council of Thailand (NRCT) Fund supported this research. We would like to thank Assoc Prof Chanvit Pornnoppadol at the Department of Psychiatry, Faculty of Medicine, Siriraj Hospital, Mahidol University for giving permission to use the Social Media Addiction Test (S-MAT), the graduate school of Chiangmai University for giving permission to use the self-esteem questionnaire, and Bangkok Entertainment Company Limited for giving permission to use a section of "WaiSabSaRaekKad" TV series as a case study in this study. Finally, we are thankful to the principal, teachers, and students of a high school in Ubon Ratchathani province for their kind cooperation in this study.

\section{Disclosure}

The authors report no conflicts of interest in this work.

\section{References}

1. Wearesocialsg [webpage on the Internet]. Digital in 2017 Global Overview; 2017 [cited July 26, 2017]. Available from: https://www. slideshare.net/wearesocialsg/digital-in-2017-global-overview. Accessed July 26, 2018.

2. Kuss DJ, Griffiths MD. Online social networking and addiction - a review of the psychological literature. Int J Environ Res Public Health. 2011;8(9):3528-3552.
3. Ahn J. The effect of social network sites on adolescents' social and academic development: current theories and controversies. J Assoc Inf Sci Technol. 2011;62(8):1435-1445.

4. Szczegielniak A, Pałka K, Krysta K. Problems associated with the use of social networks - a pilot study. Psychiatr Danub. 2013;25(Suppl 2):S212-S215.

5. Tsitsika A, Janikian M, Schoenmakers TM, et al. Internet addictive behavior in adolescence: a cross-sectional study in seven European countries. Cyberpsychol Behav Soc Netw. 2014;17(8):528-535.

6. Wolniczak I, Cáceres-Delaguila JA, Palma-Ardiles G, et al. Association between Facebook dependence and poor sleep quality: a study in a sample of undergraduate students in Peru. PLoS One. 2013;8(3):e59087.

7. Andreassen CS, Torsheim T, Brunborg GS, Pallesen S. Development of a Facebook Addiction Scale. Psychol Rep. 2012;110(2):501-517.

8. Andreassen CS, Pallesen S. Social network site addiction - an overview. Curr Pharm Des. 2014;20(25):4053-4061.

9. O'Keeffe GS, Clarke-Pearson K; Council on Communications and Media. The impact of social media on children, adolescents, and families. Pediatrics. 2011;127(4):800-804.

10. Giota KG, Kleftaras G. The role of personality and depression in problematic use of social networking sites in Greece. Cyberpsychology. 2013;7(3):1-10

11. Hanprathet N, Manwong M, Khumsri J, Yingyeun R, Phanasathit M. Facebook addiction and its relationship with mental health among Thai high school students. J Med Assoc Thai. 2015;98(Suppl 3):S81-S90.

12. Koc M, Gulyagci S. Facebook addiction among Turkish college students: the role of psychological health, demographic, and usage characteristics. Cyberpsychol Behav Soc Netw. 2013;16(4):279-284.

13. Pantic I. Online social networking and mental health. Cyberpsychol Behav Soc Netw. 2014;17(10):652-657.

14. Pernsungnern P, Pornnoppadol C, Sitdhiraksa N, Buntub D. Social media addiction: prevalence and association with depression among 7 th-12th grade students in Bangkok. In: Graduate Research Conference 2014; Khon Kaen University; 2014:1132-1138.

15. Ryan T, Chester A, Reece J, Xenos S. The uses and abuses of Facebook: a review of Facebook addiction. J Behav Addict. 2014;3(3):133-148.

16. Sadia M, Maheen K. Impact of Facebook addiction on narcissistic behavior and self-esteem among students. J Pak Med Assoc. 2015;65(3):260-263.

17. Walther B, Hanewinkel R, Morgenstern M. Effects of a brief schoolbased media literacy intervention on digital media use in adolescents: cluster randomized controlled trial. Cyberpsychol Behav Soc Netw. 2014;17(9):616-623.

18. Winkler A, Dörsing B, Rief W, Shen Y, Glombiewski JA. Treatment of Internet addiction: a meta-analysis. Clin Psychol Rev. 2013;33(2):317-329.

19. Wölfling K, Beutel ME, Dreier M, Müller KW. Treatment outcomes in patients with Internet addiction: a clinical pilot study on the effects of a cognitive-behavioral therapy program. Biomed Res Int. 2014;2014(10):425924-8

20. Cash H, Rae CD, Steel AH, Winkler A. Internet addiction: a brief summary of research and practice. Curr Psychiatry Rev. 2012;8(4):292-298.

21. Burke BL, Arkowitz H, Menchola M. The efficacy of motivational interviewing: a meta-analysis of controlled clinical trials. J Consult Clin Psychol. 2003;71(5):843-861.

22. Cushing CC, Jensen CD, Miller MB, Leffingwell TR. Meta-analysis of motivational interviewing for adolescent health behavior: efficacy beyond substance use. J Consult Clin Psychol. 2014;82(6):1212-1218.

23. Hemming K, Girling AJ, Sitch AJ, Marsh J, Lilford RJ. Sample size calculations for cluster randomised controlled trials with a fixed number of clusters. BMC Med Res Methodol. 2011;11(1):102.

24. van Breukelen GJP, Candel MJJM. Calculating sample sizes for cluster randomized trials: we can keep it simple and efficient! J Clin Epidemiol. 2012;65(11):1212-1218.

25. Wongpiromsarn Y, Nuanmanee S, Mongkol A, Wipulakorn P, Woener W. Strengths and Difficulties Questionnaire (SDQ) Thai improved version: change and administration. J Mental Health Thailand. 2011;19(2):128-134. 
26. Wongpakaran T, Wongpakaran N. A comparison of reliability and construct validity between the original and revised versions of the Rosenberg Self-Esteem Scale. Psychiatry Investig. 2012;9(1):54-58.

27. Trangkasombat U, Lapboonsup V, Havanont P. CES-D in adolescents. J Psychiatr Assoc Thailand. 1997;42(1):2-13.

28. Xu J, Shen LX, Yan CH, et al. Parent-adolescent interaction and risk of adolescent Internet addiction: a population-based study in Shanghai. BMC Psychiatry. 2014;14(1):112.

29. Lam LT. Risk factors of Internet addiction and the health effect of internet addiction on adolescents: a systematic review of longitudinal and prospective studies. Curr Psychiatry Rep. 2014;16(11):508.

30. D'Amico EJ, Houck JM, Hunter SB, Miles JNV, Osilla KC, Ewing BA. Group motivational interviewing for adolescents: change talk and alcohol and marijuana outcomes. J Consult Clin Psychol. 2015;83(1):68-80.

31. Brown RA, Abrantes AM, Minami H, et al. Motivational interviewing to reduce substance use in adolescents with psychiatric comorbidity. $J$ Subst Abuse Treat. 2015;59:20-29.

32. Navidian A, Kermansaravi F, Tabas EE, Saeedinezhad F. Efficacy of group motivational interviewing in the degree of drug craving in the addicts under the methadone maintenance treatment (MMT) in South East of Iran. Arch Psychiatr Nurs. 2016;30(2):144-149.
33. Griffiths MD, Kuss DJ, Demetrovics Z. Chapter 6 - Social networking addiction: an overview of preliminary findings. In: Rosenberg KP, Feder LC, editors. Behavioral Addictions. San Diego: Academic Press; 2014:119-141.

34. Moreno MA, Jelenchick LA, Egan KG, et al. Feeling bad on Facebook: depression disclosures by college students on a social networking site. Depress Anxiety. 2011;28(6):447-455.

35. Toseeb U, Inkster B. Online social networking sites and mental health research. Front Psychiatry. 2015;6(3):36.

36. Carli V, Durkee T, Wasserman D, et al. The association between pathological Internet use and comorbid psychopathology: a systematic review. Psychopathology. 2013;46(1):1-13.

37. Woods HC, Scott H. \#Sleepyteens: social media use in adolescence is associated with poor sleep quality, anxiety, depression and low selfesteem. J Adolesc. 2016;51:41-49.

38. Khumsri J, Yingyeun R, Mereerat M, Hanprathet N, Phanasathit M. Prevalence of Facebook addiction and related factors among Thai high school students. J Med Assoc Thai. 2015;98(Suppl 3):S51-S60.

39. Echeburua E, de Corral P. Addiction to new technologies and to online social networking in young people: a new challenge. Adicciones 2010;22(2):91-95.
Psychology Research and Behavior Management

\section{Publish your work in this journal}

Psychology Research and Behavior Management is an international, peerreviewed, open access journal focusing on the science of psychology and its application in behavior management to develop improved outcomes in the clinical, educational, sports and business arenas. Specific topics covered in the journal include: Neuroscience, memory and decision making; Behavior

\section{Dovepress}

modification and management; Clinical applications; Business and sports performance management; Social and developmental studies; Animal studies. The manuscript management system is completely online and includes a very quick and fair peer-review system, which is all easy to use. Visit http://www. dovepress.com/testimonials.php to read real quotes from published authors. 